\title{
Synthesis of a protected keto-Lysidine Analogue via Improved Prep- aration of Arabino-isoCytosine Nucleosides
}

\author{
Joseph B. Sweeney, ${ }^{*+}$ Paul A. Bethel, ${ }^{\ddagger}$ Duncan M. Gill, ${ }^{\ddagger}$ Agata M. Ochocińska, ${ }^{9}$ Anthony E. J. Walsh, ${ }^{,}$and Scar- \\ lett M. Walton ${ }^{\mathrm{X}}$
}

†Department of Chemistry, Lancaster University, Lancaster LA1 4YB, UK; ${ }^{\mathrm{y}}$ Department of Chemical Sciences, School of Applied Sciences, University of Huddersfield, Queensgate, Huddersfield, West Yorkshire, HD1 3DH, UK; ${ }^{\ddagger}$ AstraZeneca Pharmaceutical De-

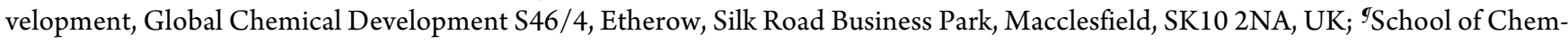
istry, Food and Pharmacy, University of Reading, PO Box 224, Whiteknights, Reading RG6 6AP, UK.

Supporting Information Placeholder

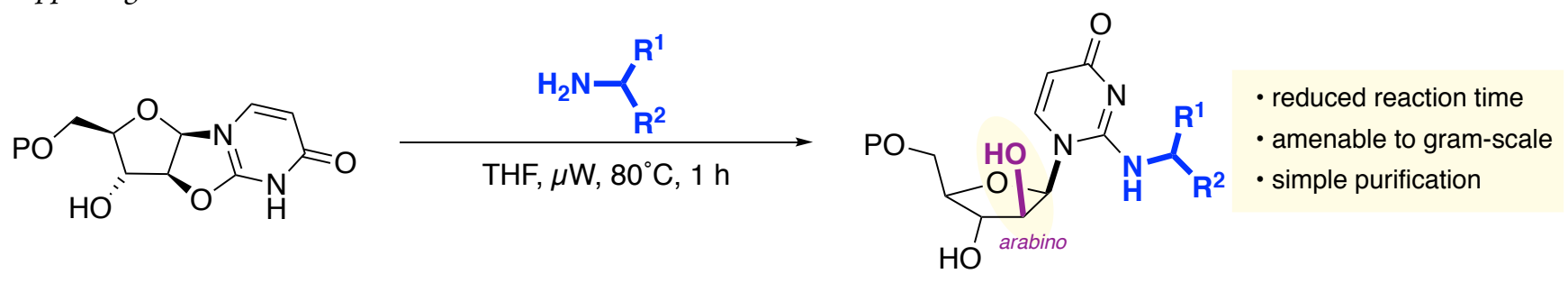

ABSTRACT: Anhydrouridines react with aliphatic amines to give $N$-alkyl isocytosines, but reported procedures often demand very long reaction times, and can be low-yielding, with narrow scope. A modified procedure for such reactions has been developed, using microwave irradiation, significantly reducing reaction time and allowing facile access to a diverse range of novel nucleosides on gram-scale. The method has been used to prepare a precursor to a novel analogue of lysidine, a naturally occurring iminonucleoside found in tRNA.

Non-coded ('unnatural') nucleoside analogues are privileged chemical motifs, possessing a diverse range of biological and clinical properties. Most nucleoside drug candidates contain modified heterocyclic components but modification to the native ribose core can also confer significant biological activity, and 2'-modified nucleosides are found at the heart of marketed antisense oligonucleotide $^{1}$ medications, including mipomersen (Kynamro, used to treat homozygous familial hypercholesterolemia) and nusinersen (Spinraza, for spinal muscular atrophy). 2'-Modified mononucleosides also exhibit biological potency, and arabino-configured nucleosides Cytarabine (ara-C 1, acute myeloid and lymphocytic leukaemias, and lymphomas; Figure 2), Clevudine (2, hepatitis B) and Fludarabine (3, chronic lymphocytic leukaemia, non-Hodgkin lymphoma) are used in the clinic, leading to great interest in methods for synthesis of this class of compound. ${ }^{2,3}$ In addition to therapeutic significance, modified nucleosides are also of great utility as structural probes and as chemical start points for functional synthetic polynucleotides. Arabino-configured antisense systems have been prepared and shown to posses interesting properties, ${ }^{4}$ and aminated arabino-isocytosines $\mathbf{4}$ are also biologically active nucleoside analogues, possessing anti-cancer activity, ${ }^{5}$ and as precursors to polynucleotides able to form duplexes with isoG-containing sequences. ${ }^{6}$ As part of a research program directed towards synthesis and testing of novel catalytic polynucleotides possessing both modified base and ribose motifs, compounds rarely reported in the literature, we sought a synthetic entry to arabino-configured isocytosines 4 .
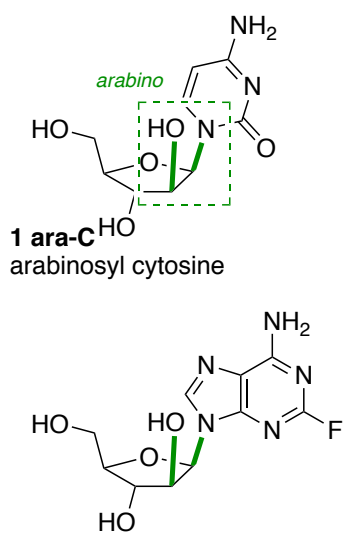

3 Fludarabine arabinosyl guanosine
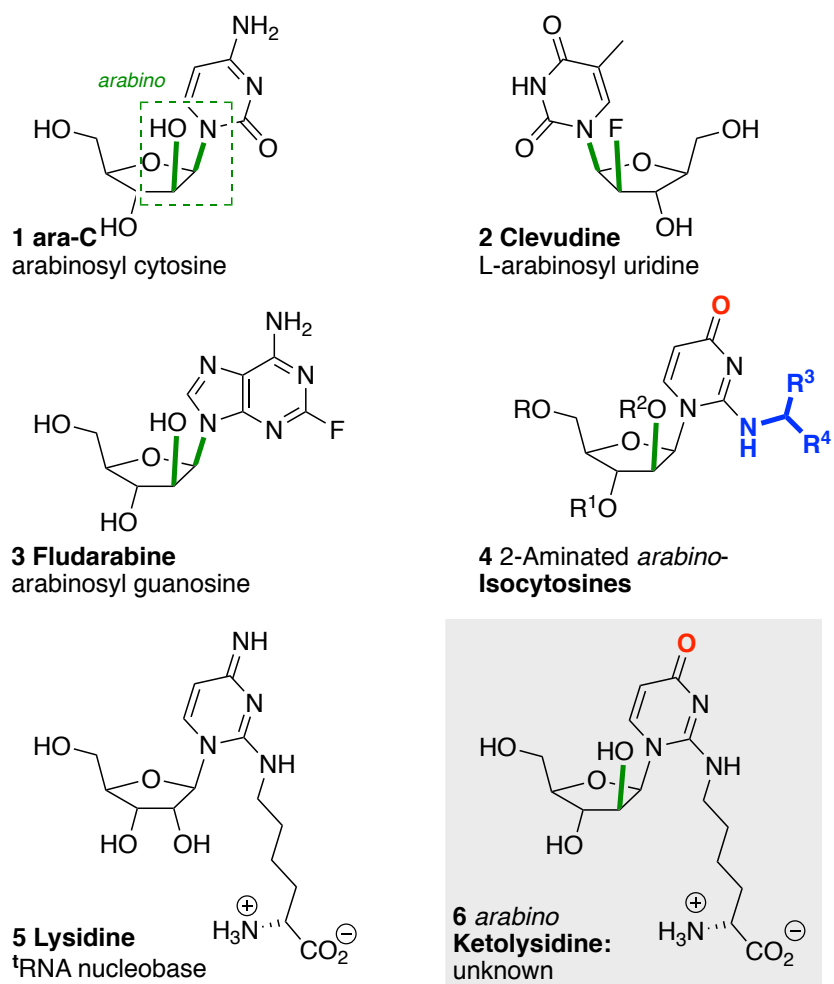

4 2-Aminated arabinoIsocytosines

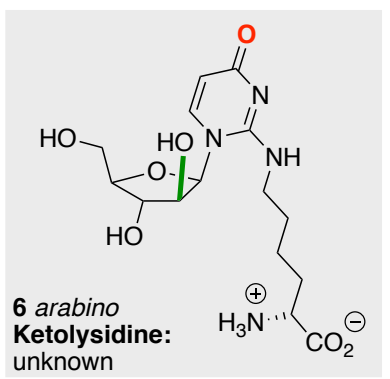

Figure 1. arabino-Nucleosides: privileged chemical motifs 
In addition, for similar purposes, we also sought access to arabino-configured analogues of the naturally occurring ${ }^{\text {tRNA nucleo- }}$ side Lysidine 5, as potential inhibitors of lysidine synthetase. ${ }^{7}$

We envisaged entry to arabino-isocytosines, including the previously unreported lysidine analogue 6 , by means of ring-opening of 2, 3'-anhydrouridines 7 by aliphatic amines (Figure 2): thus, reaction of a suitably protected lysine 8 would directly give the protected lysidine analogue. However, we found existing methods capricious and low-yielding and so sought an alternative entry to these non-coded nucleoside analogues; we report here a modified procedure which ameliorates these problems, delivering the target nucleosides on gram-scale, and representing a significant advance over the existing methodology.

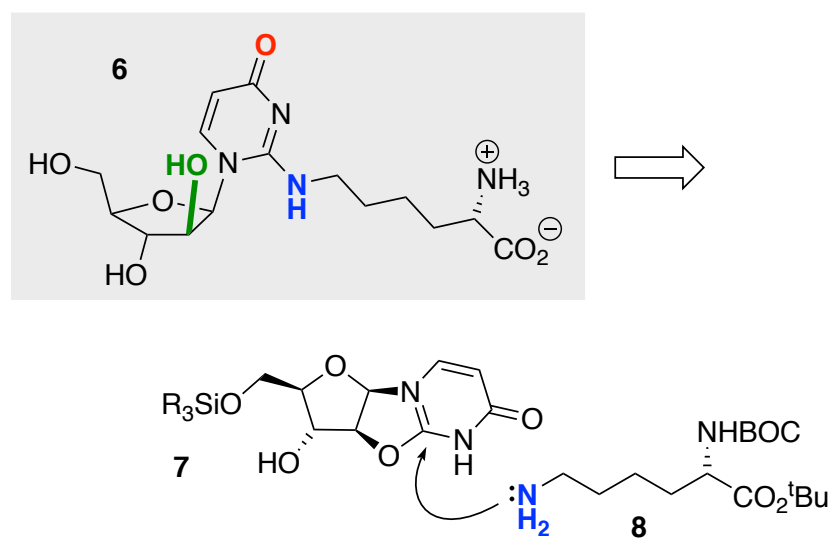

Figure 2. Arabino-ketolysidine synthesis: strategy

The ring-opening of anhydrouridine by ammonia was first reported by Todd et al; ${ }^{8}$ the method was later refined ${ }^{9}$ and broadened in scope, to include higher amines. ${ }^{10}$ In general, the ring-opening of anhydrouridine with alkylamines to give ara-isocytosines is a slow process, ${ }^{11}$ with reactions typically taking several days to reach completion (e.g., ring-opening of anhydrouridine by cyclohexylamine takes 32 days to reach completion $\left.{ }^{10}\right)$. Moreover, the isolation of aminated products is inefficient, with post-reaction derivatization of the unprotected product necessary to allow reasonable yields to be achieved. ${ }^{8}$ Prior protection of the 5'-hydroxyl group directly delivers tractable products, but does not noticeably improve the rate of reaction. The use of microwave irradiation to accelerate reactions, in particular those performed in polar solvents, is a contemporary paradigm, and we envisaged that this would be a valuable method to accelerate the ring-opening of anhydronucleosides by amines. After a screen of reaction conditions, we were, therefore, gratified to observe that anhydrouridines $7 \mathbf{b}-\mathbf{d}$ reacted with methylamine and "butylamine in THF at $80{ }^{\circ} \mathrm{C}$ at $300 \mathrm{~W}$ to give the aminated products, arabino-isocytosines $4 \mathrm{ba}, 4 \mathrm{ca}, 4 \mathrm{cb}$ and $4 \mathrm{db}$, in good yields, after only 1 hour (Table 1 ). The reaction with methylamine had not been reported in the literature, presumably due to the volatility of the amine component.

Although the ring-opened products proved stable to chromatography, showing little tendency to return to the anhydro starting material, the products could more conveniently be isolated by precipitation from the crude reaction medium.
Table 1. Nucleoside amination by ring-opening of anhydrouridine: traditional vs. microwave conditions.

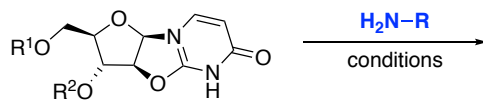

7a: $\mathrm{R}^{1}=\mathrm{R}^{2}=\mathrm{H} ; \mathbf{7 b}: \mathrm{R}^{1}=\mathrm{TBS}, \mathrm{R}^{2}=\mathrm{H}$;

7c: $R^{1}=R^{2}=$ TBS; $7 d: R^{1}=$ TBDPS, $R^{2}=H$

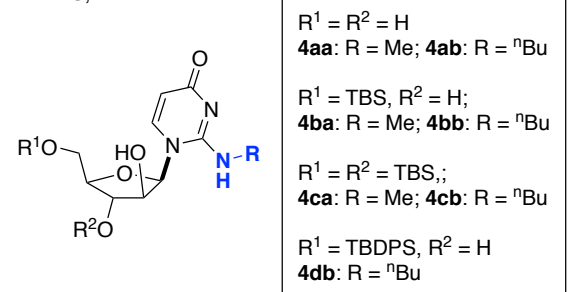

\begin{tabular}{|c|c|c|c|c|c|}
\hline 7 & $\mathbf{R}$ & conditions & $\begin{array}{c}\text { reaction } \\
\text { time } / \mathrm{h}\end{array}$ & product & yield $/ \%$ \\
\hline $7 a$ & $\mathrm{Me}$ & $\begin{array}{l}\mathrm{DMF}, 7 \text { eq. amine, } \\
\mathrm{rt}^{\mathrm{a} 10}\end{array}$ & $\mathrm{~N} / \mathrm{A}$ & $4 a a$ & $\mathrm{~N} / \mathrm{A}$ \\
\hline $7 a$ & ${ }^{\mathrm{n}} \mathrm{Bu}$ & $\begin{array}{l}\mathrm{DMF}, 7 \text { eq. amine, } \\
\mathrm{rt}^{\mathrm{a}}\end{array}$ & 72 & $4 a b$ & $71^{\mathrm{b}}$ \\
\hline $7 b^{12}$ & $\mathrm{Me}$ & $\begin{array}{l}\text { THF } 10 \text { eq. amine, } \\
\mu \mathrm{W}, 80^{\circ} \mathrm{C}\end{array}$ & 1 & $4 \mathrm{ba}$ & 89 \\
\hline $7 c^{12}$ & $\mathrm{Me}$ & $\begin{array}{l}\text { THF } 10 \text { eq. amine, } \\
\mu \mathrm{W}, 80^{\circ} \mathrm{C}\end{array}$ & 1 & $4 \mathrm{ca}$ & 65 \\
\hline $7 b$ & ${ }^{\mathrm{n}} \mathrm{Bu}$ & $\begin{array}{l}\text { THF } 10 \text { eq. amine, } \\
\mu \mathrm{W}, 120^{\circ} \mathrm{C}\end{array}$ & 1 & $4 \mathrm{bb}$ & mixture \\
\hline $7 c$ & ${ }^{\mathrm{n}} \mathrm{Bu}$ & $\begin{array}{l}\text { THF } 10 \text { eq. amine, } \\
\mu \mathrm{W}, 80^{\circ} \mathrm{C}\end{array}$ & 0.5 & $4 \mathrm{cb}$ & 55 \\
\hline $7 c$ & ${ }^{\mathrm{n}} \mathrm{Bu}$ & $\begin{array}{l}\text { THF } 10 \text { eq. amine, } \\
\mu \mathrm{W}, 120^{\circ} \mathrm{C}\end{array}$ & 0.5 & $4 \mathrm{cb}$ & 0 \\
\hline $7 \mathrm{c}$ & ${ }^{\mathrm{n}} \mathrm{Bu}$ & $\begin{array}{l}\text { THF } 10 \text { eq. amine, } \\
\mathrm{ZnCl}_{2}, \mu \mathrm{W}, 120^{\circ} \mathrm{C}\end{array}$ & 0.5 & $4 \mathrm{cb}$ & 0 \\
\hline $7 d^{13}$ & ${ }^{\mathrm{n}} \mathrm{Bu}$ & $\begin{array}{l}\text { THF } 10 \text { eq. amine, } \\
\mu \mathrm{W}, 80^{\circ} \mathrm{C}\end{array}$ & 1 & $4 \mathrm{db}$ & 68 \\
\hline
\end{tabular}

Thus the microwave-mediated procedure reduced the reaction time by $97 \%$; when compared to the reported procedure ${ }^{10}$ using other amines, the increase in the rate of reaction was even more striking (Table 2). The use of THF rather than a high-boiling polar solvent $\left(\right.$ such as $\mathrm{DMF}^{10}$ ) also represents a significant simplification in the process.

The process can be applied to a range of aliphatic amines (Figure 3), delivering arabino-2-(alkyl)amino isocytosines in good yields. The simplicity of the method enables gram-scale reactions to be carried out in short order, and the ability to isolate pure products directly from the reactions enables rapid and convenient access to novel nucleosides. 
Table 2. Microwave-mediated anhydrouridine amination: yield comparison

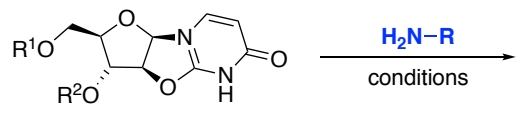

7a: $R^{1}=R^{2}=H ; 7 d: R^{1}=$ TBDPS, $R^{2}=H$

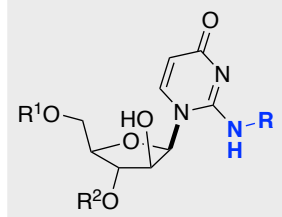

$\mathrm{R}^{1}=\mathrm{R}^{2}=\mathrm{H}$

4ab: $\mathbf{R}={ }^{\mathrm{n} B u} ;$ 4ac: $\mathbf{R}=$ Allyl

4ad: $\mathbf{R}=\mathrm{Bn}$; 4ae: $\mathbf{R}={ }^{\mathrm{C}} \mathrm{Hex}$

$\mathrm{R}^{1}=\mathrm{TBDPS}, \mathrm{R}^{2}=\mathrm{H}$

4db: $\mathbf{R}={ }^{\mathrm{n} B u}$; $4 \mathrm{dc}: \mathbf{R}=$ Allyl

4dd: $\mathbf{R}=\mathrm{Bn}$; 4de: $\mathbf{R}={ }^{\mathrm{C}} \mathrm{Hex}$

\begin{tabular}{|c|c|c|c|c|c|}
\hline 7 & $\mathbf{R}$ & conditions & $\begin{array}{l}\text { reaction } \\
\text { time } / \mathrm{h}\end{array}$ & product & yield/\% \\
\hline $7 a$ & ${ }^{\mathrm{n}} \mathrm{Bu}$ & $\begin{array}{l}\text { DMF, } 7 \\
\text { amine, rt })^{10}\end{array}$ & 36 & $4 a b$ & $71^{\mathrm{a}}$ \\
\hline $7 d$ & ${ }^{\mathrm{n}} \mathrm{Bu}$ & $\begin{array}{l}\text { THF } 10 \text { eq. } \\
\text { amine, } \mu \mathrm{W} \text {, } \\
80^{\circ} \mathrm{C}\end{array}$ & 1 & $4 d b$ & 68 \\
\hline $7 a$ & Allyl & $\begin{array}{l}\text { DMF, } 7 \\
\text { amine, } \mathrm{rt}^{10}\end{array}$ & 48 & $4 a c$ & $77^{\mathrm{a}}$ \\
\hline $7 d$ & Allyl & $\begin{array}{l}\text { THF } 10 \text { eq. } \\
\text { amine, } \mu \mathrm{W}, \\
80^{\circ} \mathrm{C}\end{array}$ & 1 & $4 d c$ & 66 \\
\hline $7 a$ & Benzyl & $\begin{array}{l}\text { DMF, } 7 \\
\text { amine, } \mathrm{rt}^{10}\end{array}$ & 180 & $4 \mathrm{ad}$ & $90^{\mathrm{a}}$ \\
\hline $7 d$ & Benzyl & $\begin{array}{l}\text { THF } 10 \text { eq. } \\
\text { amine, } \mu \mathrm{W}, \\
80^{\circ} \mathrm{C}\end{array}$ & 1 & $4 d d$ & 56 \\
\hline $7 a$ & ${ }^{c} \mathrm{Hex}$ & $\begin{array}{l}\text { DMF, } 7 \\
\text { amine, } \mathrm{rt}^{10}\end{array}$ & 384 & $4 \mathrm{ae}$ & $72^{a}$ \\
\hline $7 d$ & ${ }^{\mathrm{c}} \mathrm{Hex}$ & $\begin{array}{l}\text { THF } 10 \text { eq. } \\
\text { amine, } \mu \mathrm{W}, \\
80^{\circ} \mathrm{C}\end{array}$ & 1 & $4 \mathrm{de}$ & 51 \\
\hline
\end{tabular}

${ }^{\text {a }}$ Yield of corresponding triacetate

Armed with a new and efficient entry into 2-(alkyl)amino isocytosine nucleosides, we turned our attention to our original target molecule, ketocytosine analogue 6 , and we were delighted to observe that reaction of lysine derivative 8 with anhydrouridine $7 \mathrm{~d}$ delivered the key product 9 (a protected precursor to 6) in excellent yield (Scheme 1).
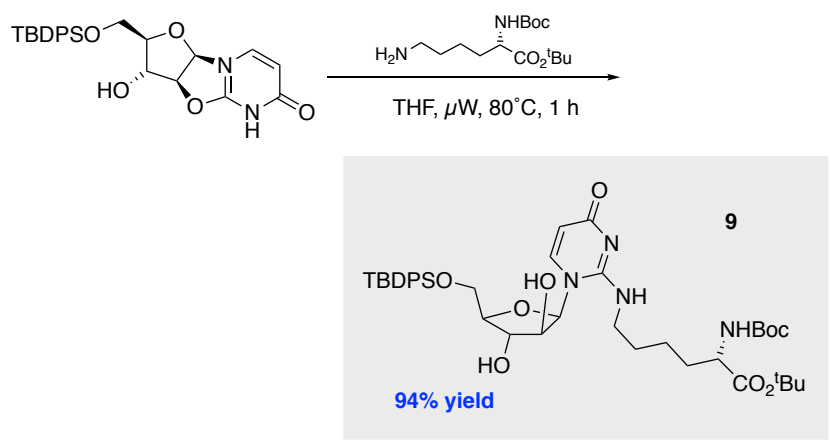

Scheme 1. Synthesis of novel ketolysidine derivative 9.
In summary, we have reported an improved method for amination of 2,2'-anhydrouridine, enabling a practical and high yielding entry to a range of 2 -aminated nucleosides. We are currently engaged in the use of this technology to deliver novel analogues of bioactive nucleosides.
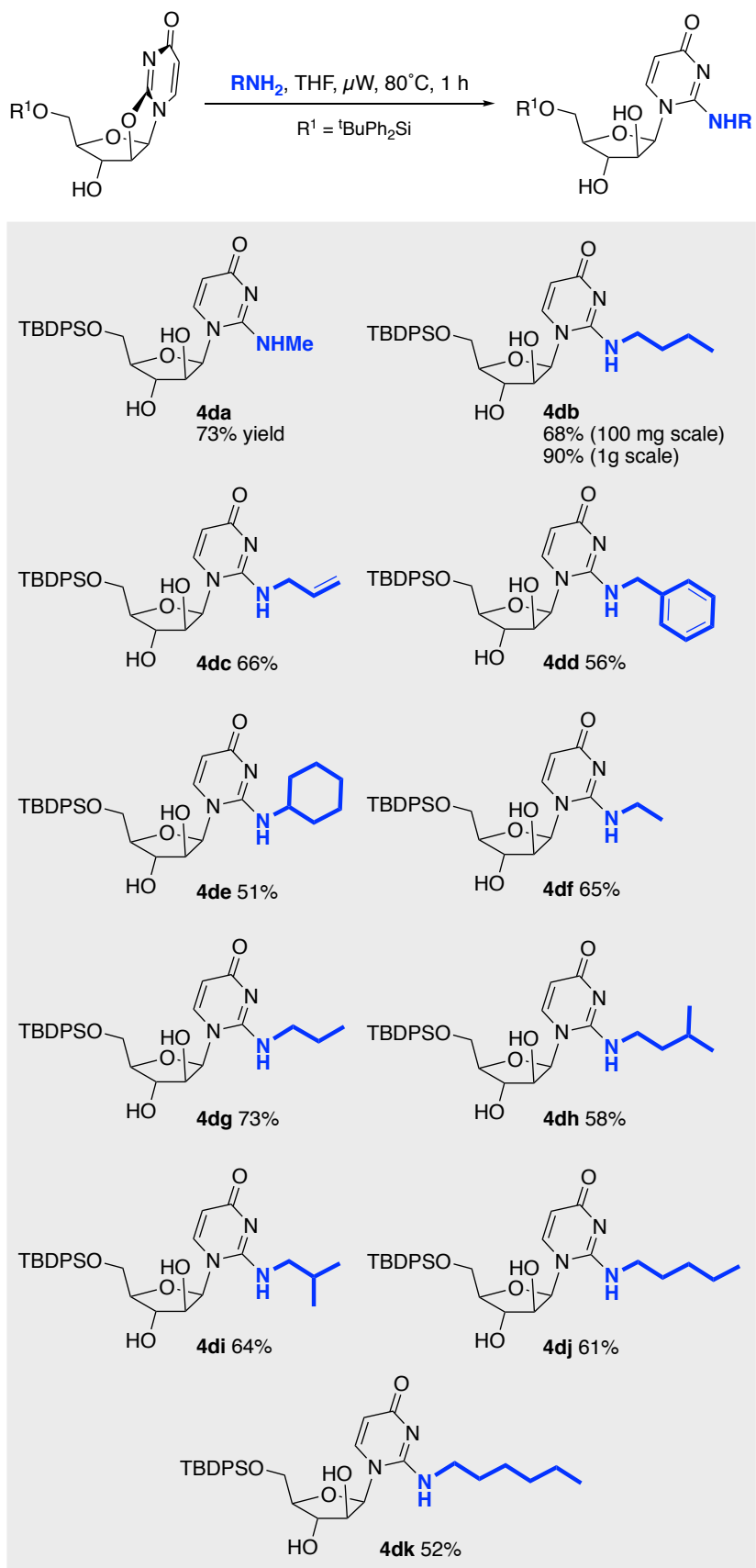

Figure 3. Amination of 5'-O-TBDPS-2,2'-Anhydrouridine: scope

\section{ASSOCIATED CONTENT}

\section{Supporting Information}

Experimental details and associated spectral data. The Supporting Information is available free of charge on the ACS Publications website. 


\section{AUTHOR INFORMATION}

\section{Corresponding Author}

*j.sweeney1@lancaster.ac.uk.

\section{ACKNOWLEDGMENT}

We thank EPSRC, AstraZeneca and the Universities of Huddersfield and Reading for funding (studentships to A. E. J. W., and S. M. W., and A. M. O., respectively). J. B. S. thanks the Royal Society, for provision of an Industry Fellowship.

\section{REFERENCES}

1. Khvorova, A.; Watts, J. K. Nat. Biotech. 2017, 35, 238-248

2. For recent synthetic activity in the area, see: Dostie, S.; Prevóst, M. Guindon, Y. J. Org. Chem. 2012, 77, 7176-7186;

3. Ewald, B.; Sampath, D.; Plunkett, W. Oncogene 2008, 27, 65226537.

4. (a) Resmini, M.; Pfleiderer, W. Helv. Chim. Acta 1993, 76, 158 (b) Damha, M. J.; Wilds, C. J.; Noronha, A.; Brukner, I.; Borkow, G.; Arion, D.; Parniak, M. A. J. Am. Chem. Soc. 1998, 120, 12976-12977; (c) Li, F.; Sarkhel, S.; Wilds, C. J.; Wawrzak, Z.; Prakash, T. P.; Manoharan, M.; Egli, M. Biochemistry 2006, 45, 4141-4152 4141
5. Krizmanić, I.; Višnjevac, A.; Luić, M.; Glavaš-Obrovac, L.; Žinić, M.; Žinić, B́ Tetrahedron 2003, 59, 4047-4057.

6. Ozaki, H.; Nakajima, K.; Tatsui, K.; Izumi, C.; Kuwahara, M.; Sawai, H. Bioorg. Med. Chem. Let. 2003, 13, 2441-2443.

7. a). Suzuki, T.; Miyauchi, K. FEBS Letters 2010, 584, 272-277; b) Shapiro A. B.; Plant, H.; Walsh, J.; Sylvester, M.; Hu, J.; Gao, N.; Livchak, S.; Tentarelli, S.; Thresher, J.J. Biomol Screen. 2014, 19, 1137-1146.

8. Brown, D. M.; Parihar, D. B.; Todd, A. R.; Varadarjan, S. J. Chem. Soc., 1958, 3028-3035.

9. Doerr, I. L.; Fox, J. J. J. Org. Chem., 1967, 32, 1462-1471.

10. Delia, T. J.; Berańek, J. J. Carbohydr., Nucleosides Nucleotides 1977, 4, 349-362.

11. See, for instance: Ozaki, H.;Nakajima, K.;Tatsui, K.; Izumi, C.; Kuwahara M.; Sawai, H. Bioorg. Med. Chem. Lett. 2003, 13, 2441-2443.

12. Ferreri, C.; Costantino, C.; Romeo, R.;Chatgilialoglu, C. Tetrahedron Lett. 1999, 40, 1197-1200.

13. Sebesta, D. P.; Rourke, S. S. O.; Martinez, R. L.; Piekcn, W. A.; McGee, D. P. C. Tetrahedron 1996, 52, 14385-14402. 